\title{
When Do Analysts Adjust for Biases in Management Guidance? Effects of Guidance Track Record and Analysts' Incentives*
}

\author{
HUN-TONG TAN, Nanyang Technological University
}

ROBERT LIBBY, Cornell University

JAMES E. HUNTON, Bentley University and Erasmus

\section{Introduction}

Research in accounting indicates that management has strong preferences for actual earnings to exceed market expectations or analysts' consensus forecast (e.g. Brown 2001; Matsumoto 2002). Research also indicates that management tends to issue downwardly-biased guidance (Soffer, Thiagarajan, and Walther 2000; Choi and Ziebart 2002; Baik and Jiang 2006). To the extent that analysts adjust for the downward bias in management's guidance by issuing forecasts that are above management's guidance, they would increase the likelihood that the firm's actual earnings will miss analysts' forecasts, thereby resulting in adverse stock price impact for the firm. However, prior archival and experimental research indicates that analysts do not fully adjust their forecasts for the downward bias in management's earnings guidance issued between quarterly earnings announcements (e.g., Cotter, Tuna, and Wysocki 2006; Tan, Libby, and Hunton 2002). ${ }^{1}$ This adjustment failure accounts in part for the predominance of firms with actual earnings that meet or beat the consensus analysts' forecast (e.g., Bartoy, Givoly, and Hayn 2002; Richardson, Teoh, and Wysocki 2004). Prior research has examined potential explanations for the bias in management guidance (e.g., Skinner and Sloan 2002; Richardson et al. 2004), but not the causes of analysts' adjustment failure.

Our study examines how analysts' incentives might interact with the consistency and magnitude of bias in management's guidance in determining

\footnotetext{
* Accepted by Michel Magnan. We would like to thank the editor (Michel Magnan) and anonymous referees, our colleagues at Bentley University, Cornell University, and Nanyang Technological University, workshop participants at the Indian School of Business, Indiana University, Notre Dame University, and the University of Texas at Austin for their helpful comments, as well as Nicholas Seybert and Bo Zhou for research assistance.

1. We define earnings guidance (also called an earnings warning) as a management forecast of earnings for the current quarter issued during the three months between quarterly earnings announcement dates.
}

Contemporary Accounting Research Vol. 27 No. 1 (Spring 2010) pp. 187-208 (C CAAA doi:10.1111/j.1911-3846.2010.01006.x 
the extent to which analysts adjust their earnings estimates for the known bias. Specifically, we address two related questions in two experiments: (a) does the consistency or inconsistency in management guidance bias over time affect the extent to which incentives influence analysts' bias adjustments (Experiment 1); and, (b) when analysts have a high incentive to preserve a good relationship with management, will the magnitude of management guidance bias influence the extent to which analysts adjust (Experiment 2)? We use an experimental rather than an archival approach to investigate these issues to hold constant firm characteristics, obtain clean measures of analysts' incentives, and control for differences in intervening events for firms with consistent and inconsistent guidance bias.

Understanding the circumstances under which analysts adjust (or fail to adjust) for guidance bias is important because analysts are important financial intermediaries and their failure to adjust for guidance bias potentially allows firms to strategically meet or beat analysts' consensus forecast (Bartov et al. 2002; Cotter et al. 2006), with potential adverse consequences for investors' welfare. Gaining insight into the causes of bias in analysts' forecasts can help investors who rely on such forecasts make their own bias adjustments and aid regulators in determining more effective remedies should such bias be judged to be detrimental to investors' interests (e.g., Levitt 1998; Cox 2005).

In Experiment 1, 47 experienced sell-side analysts make earnings forecasts in response to management guidance for the current quarter. We manipulate guidance track record by providing a summary table indicating that guidance bias is consistent or inconsistent over time. We manipulate analysts' incentives by instructing them that their only concern is being accurate (accuracy incentives) or that they have developed good relationship with management over time (relationship incentives). The mean guidance bias (guidance minus actual) in prior periods is held constant at $-\$ 0.01$ (i.e., downwardly-biased by 1 cent). The results indicate that analysts with accuracy incentives adjust for the downward guidance bias, while those with relationship incentives do not. The difference in bias adjustment between analysts with accuracy versus relationship incentives is magnified when the guidance track record is inconsistent. A striking result in Experiment 1 is that analysts with relationship incentives fail to adjust for guidance bias even when the guidance track record shows the same guidance bias of 1 cent in each period. This suggests that analysts with relationship incentives are reluctant to adjust their forecasts by even one cent when this may lead to the firm failing to beat those forecasts. In a post-experiment debriefing, analysts indicate that issuing forecasts above management's guidance would damage their relationship with management, suggesting that analysts' failure to adjust for known guidance bias when they have high relationship incentives may be intentional.

In Experiment 2, we assess whether analysts with relationship incentives are more likely to adjust for guidance bias when the average magnitude of 
the guidance bias is larger ( -2 cents), given that larger guidance bias allows the analyst to adjust without causing the firm to miss the forecasts. Thirtyfour experienced sell-side analysts are given the same relationship incentives instruction as in Experiment 1 and are assigned to either the consistent or inconsistent track record conditions. While analysts in both conditions adjust to some degree, analysts make a larger adjustment in the consistent condition relative to the inconsistent condition. The overall magnitude of the upward adjustment is about one cent, which is smaller than the average two cents downward bias evident from the track record. The findings in Experiments 1 and 2 are consistent with an elastic justification explanation (Hsee 1995), which predicts that analysts with relationship (versus accuracy) incentives will use the ambiguity in the inconsistent guidance track record to avoid adjusting for guidance bias, subject to the constraint that any adjustment does not cause a missed forecast.

Cumulatively, our findings suggest that multiple factors contribute to the somewhat paradoxical findings that analysts fail to fully adjust for downwardly-biased management guidance, even though they appear to be aware of this general bias amongst reporting firms. We demonstrate that incentive factors (accuracy versus relationship) matter, and that the effects of incentives are constrained by the historical consisteney and magnitude of guidance bias. The current study also contributes to the behavioral decision making literature by demonstrating constraints to the influence of elastic justification (Hsee 1995) in an important business setting.

In the following sections, we develop our hypotheses, describe the experiments and their results, and conclude with a discussion of the implications of our findings and limitations of our paper.

\section{Hypothesis development}

\section{Management guidance contributes to beatable forecasts}

Prior studies indicate that management earnings guidance issued within three months of the earnings announcement date is typically downwardly biased (e.g., Soffer et al. 2000; Choi and Ziebart 2002; Baik and Jiang 2006; Cotter et al. 2006). For example, in the most recent sample of 7,671 firm quarters of earnings guidance issued during the period 1995 to 2002, for the point estimate or midpoint of range guidance, 52 percent are downwardly biased, 19 percent neutral, and 29 percent upwardly biased (Baik and Jiang 2006). Among those firms with downwardly biased guidance, the median forecast error is 8 percent. ${ }^{2}$

Prior studies also suggest that the bias in short-term management guidance greatly increases the likelihood that analysts will reduce their forecasts during the quarter to beatable levels. Cotter et al. (2006) examine 8,198 firm quarters of guidance issued between 1995 and 2001. They find that, compared to a control sample of non-guiding firms, analysts' forecasts for

2. Bok Baik (personal communication, 2005). 
guiding firms are more optimistic before guidance is issued. ${ }^{3}$ Nevertheless, analysts' forecasts for the guiding firms are significantly less optimistic than the control sample after the guidance is issued. As a consequence, guiding firms are 1.7 times as likely to meet or beat the final consensus analyst forecast relative to a control sample. Similarly, in Baik and Jiang's (2006) sample of firms issuing guidance, actual earnings beats the consensus forecast before guidance 42 percent of the time as compared to 61 percent of the time after the issuance of the guidance. Bartov et al.'s (2002) 1983-1997 sample shows similar effects, with the magnitude increasing in more recent years. All of these findings strongly suggest that analysts revise their current quarter forecasts in response to management guidance, but do not fully adjust those forecasts for the downward bias in the management guidance. This finding is all the more striking because other research indicates that analysts are aware of guiding firms' general tendency to issue downwardlybiased guidance (Tan et al. 2002; Libby, Tan, and Hunton 2006). Prior research does indicate the economic importance and benefits to managers of meeting or beating analysts' forecasts (Bartov et a1. 2002; Skinner and Sloan 2002; Richardson et al. 2004), but does not explain why analysts appear to cooperate in this endeavor.

\section{Why don't analysts adjust for known guidance bias?}

\section{Incentive effects}

Analysts' incentives might affect the magnitude of their adjustment for known bias in management forecasts. Analysts face two conflicting incentives when they issue forecasts and research reports (Schipper 1991). They have an incentive to be accurate because their reputation within the firm and in the industry is determined in part by their accuracy, and research shows that more aceurate analysts are better rewarded and more likely to be hired by prestigious brokerage firms (e.g., Hong and Kubik 2003). On the other hand, analysts have an incentive to make forecasts that are aligned with the interests of the firms they cover. Prior research indicates that analysts' forecasts are biased because they have incentives to please management, and thereby obtain access to private information and help their firms obtain investment banking opportunities (Affleck-Graves, Davis, and Mendenhall 1990; Dugar and Nathan 1995; Hunton and McEwen 1997; Lin and McNichols 1998; Antia and Pantzalis 2006; Libby, Hunton, Tan, and Seybert 2008). Recent regulations have sought to reduce both sources of incentives that lead to biased forecasts.

Regulation FD (Fair Disclosure), effective in 2000, prohibits selective information disclosures to analysts and requires that any material non-public disclosures to analysts must be made simultaneously to the public. Also,

3. Bartov et al. (2002) also show that analysts' forecasts trend downwards during the quarter in that they move from being optimistic at the start of the quarter to being pessimistic at the end of the quarter. 
in 2002, the New York Stock Exchange and National Association of Securities Dealers implemented rules that limit communications between the research and investment departments of financial firms. However, the effectiveness of these regulations in reducing analysts' conflict of interests has been met with skepticism because firms allegedly continue to employ investment banks with analysts who are supportive of their stocks (Springsteel 2003). There is also empirical evidence that post Regulation FD, analysts who have better relations with management have greater access to questions during conference calls (Mayew 2008). Thus, it appears as though incentives to maintain a good relationship with management continue in the postRegulation FD environment.

As indicated earlier, research suggests that management earnings guidance is commonly downwardly biased (e.g., Soffer et al. 2000; Choi and Ziebart 2002; Baik and Jiang 2006; Cotter et al. 2006), which appears to reffect an intentional strategy of managing investors' expectations. Analysts who reinforce this strategy by failing to adjust or under-adjusting for known downward bias in guidance will likely be favorably received by management. Accordingly, we expect the following:

Hүротнеsis 1: Analysts' adjustment for a firm's management guidance track record will be greater when accuracy incentives are emphasized than when relationship incentives are emphasized.

\section{Track record consistency and elastic justification effects}

Research on elastic justification indicates that decision makers use ambiguity in available evidence to support actions that conform to their incentives (Hsee 1995; Schweitzer and Hsee 2002). The premise is that people care about the justifiability of their actions and judgments, and directional goals will have a greater effect when the desired conclusion can be justified based on the available information (Koonce and Mercer 2005).

In the context of management guidance, archival research shows that management's guidance track record varies in its consistency, introducing ambiguity in assessing the direction or magnitude of management's bias. For instance, Baik and Jiang (2006) find that in an eight-year period between 1995 and 2002, 50 percent of the firms that issue guidance do so three or more times. Among these firms, 68 percent are consistently downwardly biased or accurate, and 49 percent are consistently downwardly biased. ${ }^{4}$ In addition, for those firms that are consistently downwardly biased, the magnitude of the bias varies.

Thus, while we predict in Hypothesis 1 that analysts with relationship incentives are less likely to adjust for guidance bias than those with accuracy incentives, elastic justification theory (Hsee 1995) suggests that the

4. Bok Baik (personal communication, 2005). 
extent this occurs depends on track record consistency. Specifically, the difference in guidance bias adjustment between analysts with relationship versus accuracy incentives is likely larger when management's guidance track record is inconsistent (allowing for elastic justification to occur) than when it is consistent.

We first discuss the situation where analysts have accuracy incentives. When management's guidance history has a record of being consistently biased in the same direction and by the same magnitude (e.g., downwardlybiased by one cent), there is no ambiguity that a systematic pattern of guidance bias exists. Analysts with accuracy incentives are therefore likely to fully adjust for the guidance bias (i.e., in our example, adjust their forecasts upwards by one cent). When management's guidance track record is inconsistent, the nature of the adjustment by analysts with accuracy incentives depends on the pattern of guidance bias. For instance, no adjustment is likely if the pattern is completely random. On the other hand, some adjustments are likely to the extent that there is some indication of a systematic bias.

Consider the following guidance history with an inconsistent track record that we employ in our experiment (see section 3 for an explanation of this design choice): downward bias of 1 cent (Period 1), zero bias (Period 2 ), and downward bias of 2 cents (Period 3). This track record does not have a consistent direction of guidance bias in that one of the periods has no guidance bias, and the magnitude of the bias also varies over time. However, two out of the three periods involve downward guidance bias, so analysts with accuracy incentives likely infer that downward guidance bias is likely for the next quarter's guidance. Further, prior research shows that analysts place greater reliance on the most recent quarter earnings, in that the most recent period may be most predictive of management's current intentions (see Hunton and MeEwen 1997). Accordingly, analysts with accuracy incentives who seek to adjust for any downward guidance bias may place greater weight on the most recent period's guidance bias and adjust their forecasts upwards by two cents (see Figure 1).

When analysts have relationship incentives, as suggested by elastic justification theory, they are less likely to make adjustments for guidance bias when the track record shows an inconsistent as opposed to a consistent bias. With an inconsistent track record, there is ambiguity as to whether systematic guidance bias exists, and analysts with relationship incentives can use this ambiguity as justification not to fully adjust for any guidance bias. With a consistent track record, there is less ambiguity, and correspondingly less justification not to adjust.

However, an important institutional feature constrains the extent to which analysts adjust for guidance bias, even in the consistent track record situation. Specifically, a primary concern of management is to avoid missing analysts' forecasts (Bartov et al. 2002; Skinner and Sloan 2002; Richardson et al. 2004), and analysts can foster a good relationship with management by 
Figure 1 Prediction on joint effects of analysts' incentives and track record consistency

Adjustments

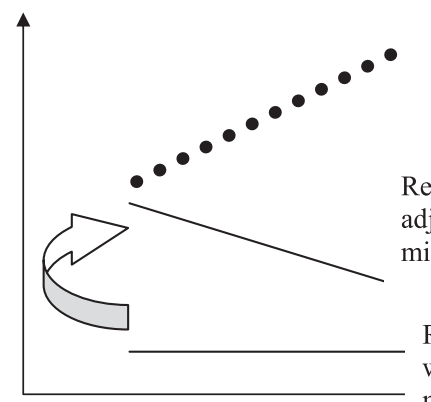

Accuracy incentives

ationship incentives - when adjustment does not cause missed forecast

Relationship incentives when adjustment causes missed forecast

Consistent downward bias

enabling them to achieve this objective. Recent research also indicates that relationship incentives magnify analysts' tendency to issue optimistic forecasts at the beginning of a period and pessimistic forecasts at the end of the period (Ke and Yu 2006; Libby et al. 2008), a pattern preferred by management as it increases the likelihood of management meeting or beating market expectations. Thus, the adjustments made by analysts with relationship incentives are constrained by whether their adjustments cause management to miss analysts' forecasts. Elastic justification theory suggests that these analysts with relationship incentives are more likely to adjust for guidance bias in the consistent (versus inconsistent) track record condition; however, we anticipate that adjustments in the consistent track record condition are made only to the extent that these adjustments do not cause a missed forecast, and smaller or no adjustments are made when a full adjustment causes a missed forecast. Figure 1 shows a graphical presentation of this prediction.

As depicted in Figure 1, we predict an interaction between incentives and track record such that the difference in adjustment for guidance bias as a function of relationship versus accuracy incentives is magnified with an inconsistent track record. We formally state this interaction hypothesis below:

HypothesIs 2: The difference in adjustment for guidance bias when relationship versus accuracy incentives are emphasized will be greater when the bias in the firm's guidance track record is inconsistent than when it is consistent.

We test these hypotheses using two experiments. In Experiment 1, we test Hypothesis 1 and Hypothesis 2 in a setting where analysts are given summaries of management guidance and actual earnings (the management guidance track record) over three prior periods. We manipulate both analysts' 
incentives (relationship versus accuracy) and track record (consistent versus inconsistent). We design the track record such that it exhibits an average downward bias of one cent, so that it corresponds to the average guidance error found in archival studies (Baik and Jiang 2006). In this case, any upward adjustment (assuming that analysts do not make half-cent adjustments) will lead the firm to miss or at best meet their guidance. In Experiment 2, we use a design that is a subset of that employed in Experiment 1 to further examine Hypothesis 2 and test the boundaries of when analysts would adjust for guidance bias. Specifically, we assess whether analysts with relationship incentives exhibit the same effects of a consistent versus inconsistent track record when the magnitude of the downward bias is raised to two cents. In this situation, an adjustment of one cent will still enable the firm to beat its guidance. We anticipate that analysts with relationship incentives will be more willing to make adjustments for guidance bias in this situation.

\section{Experiment 1: Effect of incentives and track record consistency}

Experiment 1 is designed to test whether incentives to preserve a good relationship with management (versus incentives to be accurate) curtail analyst adjustments for the bias, and whether the consistency in guidance bias over time moderates this differential adjustment for guidance bias.

\section{Method}

Our design is a $2 \times 2$ between-subjects design, with incentives (accuracy, relationship) and track record (consistent, inconsistent) as independent variables. Participants are 47 experienced sell-side financial analysts employed by a major worldwide investment banking, trading, and brokerage firm. They have an average of 11 years of analyst experience. All but three are chartered financial analysts.

Analysts complete the task during the firm's training course. ${ }^{5}$ As an incentive to participate, each analyst is provided a $\$ 50$ contribution to a charity of his/her choice. The trainer is briefed by one of the researchers in advance on the administration of the experiment, and provided with the research instruments sorted in random order. Each research instrument comprises two sealed envelopes, one containing the case materials and response sheets, and the other containing the debriefing and demographic questions. The trainer is unaware of the experimental conditions.

The case materials contain background information about a company called Kappa, Inc., a manufacturer of semiconductor and telecommunication materials. The analysts are provided with a table including the quarterly

5. Analysts completed this experiment in the afternoon. Earlier in the morning, they completed another unrelated experiment. We create a dummy variable that denotes the experimental condition analysts are in during the morning experiment. No results change when we include this dummy variable as a covariate or as another independent variable, and the dummy variable and its interactions with the afternoon experimental treatments are not significant. 
actual earnings per share for fiscal years 2003, 2004 and 2005, as well as the first quarter of 2006. The table includes guidance given in three of the prior quarters. Analysts are also given the consensus analyst earnings per share forecast for the second quarter $(\$ 0.24)$ and full year $(\$ 0.78)$ of 2006. Next, they read the following earnings guidance statement from Kappa management, which is issued on May 31, 2006:

The company expects earnings per share for the second quarter ending June 30, 2006 to be below expectations due to weaker than expected sales. Earnings per share are estimated to be approximately $\$ 0.18$ for the quarter.

The first manipulation focuses on analysts' incentives. In this manipulation, we do not manipulate actual incentives per se, but provide instructions designed to allow our participating professionals to bring their knowledge of and behavior learned in response to real world incentives to our experiment (Libby, Bloomfield, and Nelson 2002, 803). Following the accuracy/relationship with management tradeoff described by Schipper 1991, in the accuracy condition, analysts read the following statement: "Assume that your only concern is the accuracy of your forecast." In the relationship condition, analysts read the following statement: "Assume that over time, you have gradually developed a good professional relationship with Kappa management."6 Given that analysts face dual incentives to be accurate and to please management (Schipper 1991), we expect that the latter statement will induce greater incentive to be biased towards pleasing management and thus a lower propensity to adjust for guidance bias, while the former statement will induce lesser incentive towards pleasing management.

The history of management's earnings guidance is manipulated at two levels: consistent or inconsistent pattern of downwardly-biased earnings guidance. This history is shown in a summary table of guidance issued and actual earnings subsequently announced for each period; details are shown in Table 1. $?^{7}$ This format is designed to ensure that participants are aware of the firm's guidance track record.

In the consistent condition, analysts see a table of earnings and guidance history which reveals that management's guidance is consistently lower than actual earnings by the same amount $(\$ 0.01)$ in each period. We use a guidance error (guidance - actual) of minus (-) $\$ 0.01$ because this corresponds to the whole cent closest to the median guidance error in the

6. This incentives manipulation is the same as that used effectively in Libby et al. 2008 .

7. This situation is analogous to one where analysts review summary records of management guidance and the subsequent earnings releases, and identify a consistent pattern of guidance bias. Our discussion with a senior director of the participating firm indicates that analysts track and keep records of the guidance issued and actual earnings reported by firms that they follow. 
Baik and Jiang (2006) downwardly biased guidance sample. ${ }^{8}$ In the inconsistent condition, they see the same actual earnings per share. We impose a few conditions in designing the guidance history for the inconsistent

\section{TABLE 1}

Experiment 1: Details of track record manipulations

Panel A: Consistent track record manipulation

\begin{tabular}{|c|c|c|c|c|c|}
\hline Year & $\begin{array}{c}\text { First } \\
\text { quarter }\end{array}$ & $\begin{array}{l}\text { Second } \\
\text { quarter }\end{array}$ & $\begin{array}{l}\text { Third } \\
\text { quarter }\end{array}$ & $\begin{array}{l}\text { Fourth } \\
\text { quarter }\end{array}$ & Year \\
\hline \multicolumn{6}{|l|}{ Fiscal 2003} \\
\hline Guidance & & & & 0.14 & \\
\hline Actual EPS & 0.06 & 0.12 & 0.18 & 0.15 & \\
\hline \multicolumn{6}{|l|}{ Fiscal 2004} \\
\hline Guidance & & 0.16 & & & \\
\hline Actual EPS & 0.19 & 0.17 & & & 0.75 \\
\hline \multicolumn{6}{|l|}{ Fiscal 2005} \\
\hline \multicolumn{6}{|l|}{ Guidance } \\
\hline Actual EPS & 0.21 & 0.25 & & 0.18 & 0.80 \\
\hline \multicolumn{6}{|l|}{ Fiscal 2006} \\
\hline \multicolumn{6}{|l|}{ Guidance } \\
\hline Actual EPS & 0.19 & & & & \\
\hline
\end{tabular}

Panel B: Inconsistent track record manipulation

\begin{tabular}{|c|c|c|c|c|c|}
\hline Year & $\begin{array}{l}\mathrm{Fi} \\
\mathrm{qu}\end{array}$ & $\begin{array}{l}\text { Secon } \\
\text { quarte }\end{array}$ & $\begin{array}{l}\text { Third } \\
\text { quarter }\end{array}$ & $\begin{array}{l}\text { Fourth } \\
\text { quarter }\end{array}$ & Year \\
\hline \multicolumn{6}{|l|}{ Fiscal 2003} \\
\hline Guidance & & & & 0.14 & \\
\hline Actual EPS & & 0.12 & 0.18 & 0.15 & 0.51 \\
\hline \multicolumn{6}{|l|}{ Fiscal 2004} \\
\hline Gu & & 0.17 & & & \\
\hline Actual EPS & 0.19 & 0.17 & 0.19 & 0.2 & 0.75 \\
\hline \multicolumn{6}{|l|}{ Fiscal 2005} \\
\hline Guidance & & & 0.14 & & \\
\hline Actual EPS & 0.21 & 0.25 & 0.16 & 0.18 & 0.8 \\
\hline \multicolumn{6}{|l|}{ Fiscal 2006} \\
\hline \multicolumn{6}{|l|}{ Guidance } \\
\hline Actual EPS & 0.19 & & & & \\
\hline
\end{tabular}

(The table is continued on the next page.)

8. The median guidance error [(Guidance - Actual)/Absolute (Actual)] of their sample is -.079 . The value selected, $-\$ 0.01$, is the whole cent nearest that amount (average guidance error $=-.063$ for the three periods). 
TABLE 1 (Continued)

Notes:

Experiment 1 manipulates two between-subjects variables: Track Record (consistent, inconsistent) and Incentives (accurate, relationship). The Track Record manipulation varies the consistency in the downward bias associated with management guidance issued by management in prior periods. Panels A and B show the firm's guidance track record that is shown to analysts. For both consistent and inconsistent Track Record manipulations, the average guidance bias over the three periods is a downward bias of one cent $(-\$ 0.01)$. In the consistent Track Record manipulation, each period is associated with the same amount of downward bias of one cent. In the inconsistent Track Record manipulation, Fiscal 2003 has a downward bias of one cent, Fiscal 2004 has no bias, and Fiscal 2005 has a downward bias of two cents.

condition. First, the error in management's guidance is to vary in each period, but the average guidance error over the three periods is held constant at $-\$ 0.01$. Second, there must be evidence of a downward guidance bias in two (but not all three) periods. The reason is that a downward guidance bias in all three periods would suggest a consistent (rather than inconsistent) downward guidance history, even if the magnitude of the bias were to vary in each period; in contrast, having a downward guidance bias in only one of the periods might not establish any track record. Third, the magnitude of the downward guidance bias is to differ in each of these two periods. Otherwise, having the magnitude of the downward guidance bias constant in two of the periods may also suggest a consistent rather than inconsistent track record. Given these conditions, we design the inconsistent condition to be one where guidance is downwardly biased by one cent in Fiscal 2003, accurate with zero bias in Fiscal 2004, and downwardly biased by two cents in Fiscal 2005. We design the last, rather than the first, fiscal year to have the larger downward bias of two cents for the following reason: if the first fiscal year had the downward bias of two cents and the last fiscal year had the downward bias of one cent (a downward trend in bias), a finding that analysts in the management relations condition do not adjust for guidance bias (Hypothesis 2) could be attributable either to the presence of incentives or the possibility that the downward guidance bias is decreasing over time. We design the second fiscal year to have zero bias in order to keep the mean guidance error across the three periods at $-\$ 0.01$.

Analysts are asked to provide earnings per share forecasts for the quarter ending June 30, 2006, full year ending December 31, 2006, and full year ending December 31, 2007. Additionally, they record their level of confidence in the accuracy of their forecasts $(0 \%=$ not at all confident, $100 \%=$ extremely confident). Afterward, they complete the debriefing and demographic questions. 
TABLE 2

Experiment 1 results

Panel A: Mean analysts' forecasts (standard deviation in parentheses)

\begin{tabular}{|c|c|c|c|c|}
\hline \multicolumn{5}{|c|}{ Track record } \\
\hline \multirow{2}{*}{$\begin{array}{l}\text { Incentives } \\
\text { Amount }\end{array}$} & \multicolumn{2}{|c|}{ Consistent } & \multicolumn{2}{|c|}{ Inconsistent } \\
\hline & $\begin{array}{l}\text { Accuracy } \\
(n=12)\end{array}$ & $\begin{array}{l}\text { Relationship } \\
\quad(n=12)\end{array}$ & $\begin{array}{l}\text { Accuracy } \\
(n=11)\end{array}$ & $\begin{array}{l}\text { Relationship } \\
\quad(n=12)\end{array}$ \\
\hline \multicolumn{5}{|l|}{ Information provided: } \\
\hline Point guidance & $\$ 0.18$ & $\$ 0.18$ & $\$ 0.18$ & \\
\hline Mean guidance bias & $-\$ 0.01$ & $-\$ 0.01$ & $-\$ 0.01$ & \\
\hline \multicolumn{5}{|l|}{ Analyst forecasts: } \\
\hline Current quarter EPS & $\begin{array}{c}0.1917 \\
(0.0039)\end{array}$ & $\begin{array}{c}0.1825 \\
(0.0075)\end{array}$ & & $(0.0058)$ \\
\hline $\begin{array}{l}\text { Adjustment to current } \\
\text { quarter's guidance of } \$ 0.18 \\
\text { (forecast - guidance) }\end{array}$ & $+0.0117 *$ & +0.00 & & -0.0017 \\
\hline
\end{tabular}

Panel B: ANOVA Results for adjustment to current quarter's guidance

\begin{tabular}{llrrrr}
\hline Source & SS & df & MSE & $F$-Statistic & $p$-value \\
\hline Track Record & 0.0002 & 1 & 0.0002 & 2.96 & 0.092 \\
Incentives & 0.0037 & 1 & 0.0037 & 48.86 & 0.000 \\
Track Record x Incentives & 0.0009 & 1 & 0.0009 & 11.34 & 0.002 \\
Error & 0.0032 & 43 & 0.0001 & & \\
\hline
\end{tabular}

Notes:

Experiment 1 manipulates two between-subjects variables: Track Record (consistent, inconsistent) and Incentives (accurate, relationship). The Track Record yariable manipulates whether the firm's prior guidance is associated with a consistent or inconsistent downward bias. The Incentives variable manipulates whether analysts are informed that their only concern is the accuracy of their forecasts (accuracy incentives), or that they have developed a good relationship with the firm's management over time (relationship incentives).

* $\quad$ Significantly different from zero; $p=0.000$.

\section{Results}

\section{Manipulation checks}

As a check on the incentives manipulation, we ask analysts whether the instructions indicate that they have gradually developed a good professional relationship with management over time, or that their only concern is the accuracy of their earnings forecasts. All analysts in their respective 
treatment conditions correctly respond to this question. We ask two manipulation check questions related to the track record treatment. The first question asks analysts to indicate on a nine-point scale (1: much too low; 5: about right; 9: much too high) whether in prior periods, Kappa's guidance is generally too high, too low, or about right compared to the actual earnings announcement. The mean response is 2.40 (range 1 to 4 ) indicating that all analysts are aware that the guidance is downwardly biased. The second question asks whether Kappa's earnings guidance in prior periods is always too low by the same amount. Every participant responds correctly to this question ("yes" for those in the consistent condition, "no" for those in the inconsistent condition).

\section{Hypothesis tests}

Our primary dependent variable is the analysts' adjustment to management guidance issued in the current quarter (forecast - guidance). Table 2, panel A shows descriptive statistics for analysts' forecasts for the current quarter and adjustments to management guidance. Table 2, panel B reports results of a $2 \times 2$ analysis of variance (ANOVA), with incentives and track record conditions as between-subjects factors and adjustment to management guidance in the current quarter as the dependent variable. We find a marginally significant main effect of track record $(p=0.092)$, a significant main effect of incentives ( $\mathrm{p}=0.000)$, and a significant track record by incentives interaction $(p=0.002)$.

Hypothesis 1 predicts that analysts' adjustment for bias in the management guidance track record will be larger for analysts in the accuracy condition than those in the relationship condition (a main effect). Consistent with Hypothesis 1, analysts' bias adjustment is greater in the accuracy condition than in the relationship condition $(t=6.732, p=0.000$; one-tailed $){ }^{9}$ In the accuracy condition, analysts' mean bias adjustment is +1.78 cents, which is significantly greater than zero $(t=7.098, p=0.000)$. However, in the relationship condition, their mean bias adjustment is +0.04 cents, which is not significantly different from zero $(t=0.296, p=0.770)$. Bias adjustment is greater for analysts in the accuracy condition both when track record is consistent $(t=3.743, p=0.002)$ and inconsistent $(t=5.637$, $p=0.000)$.

Hypothesis 2 predicts that the difference in analysts' adjustment for guidance bias in the accuracy and relationship conditions will be greater when the track record is inconsistent than when it is consistent. The difference in bias adjustment between analysts in the two incentive conditions is +2.62 cents when track record is inconsistent and +0.92 cents when it is consistent. A planned contrast test indicates that, as predicted by Hypothesis 2, this difference is significant ( $t=3.243, p=0.002$; one-tailed).

9. The forecasts have unequal variances, and contrast tests we report adjust for unequal variances. 
For analysts in the accuracy condition, bias adjustments are always statistically greater than zero whether the track record is consistent (mean $=$ +1.17 cents, $t=10.383, p=0.000$ ) or inconsistent (mean $=+2.45$ cents, $t=5.655, p=0.000$ ). This bias adjustment is larger in the inconsistent condition than in the consistent condition $(t=2.872, p=0.015)$, consistent with the pattern depicted in Figure 1 for the accuracy condition, reflecting the larger bias in the most recent period.

For analysts in the relationship condition, their next-period forecasts are never significantly different from management guidance of 18 cents. Mean bias adjustment is not different from zero in either the consistent condition (mean $=0.25$ cents, $t=1.149, p=0.275$ ) or inconsistent condition (mean $=-0.17$ cents, $t=-1.000, p=0.339$ ), and there is no significant difference between the mean bias adjustment between the consistent and inconsistent conditions $(t=1.177, p=0.246){ }^{10}$ This pattern of results matches the flat line depicted for the relationship condition depicted in Figure 1 and is congruent with the explanation that analysts do not adjust for guidance bias when any such adjustment would cause risk of management missing the analysts' forecasts (Figure 1). ${ }^{11}$

\section{Debriefing}

In the post-experiment debriefing questionnaire, we ask analysts whether their relationship with clients who purchase a stock would be harmed or improved if the firm beats their most recent quarterly earnings forecast. On a scale from 1 (harm) to 9 (improve), the mean response is 8.83 , significantly greater than the midpoint of $5(t=69.12, p<.0001)$. We also ask analysts whether their relationship with company management would be harmed or improved if they regularly issue forecasts above management earnings guidance and the company fails to meet or beat these forecasts. On the same nine-point scale, the mean response is 2.23 , significantly lower than the midpoint of $5(t=-22.59, p<.0001)$. This finding is consistent

10. We repeat our analyses using analysts' 12 -month current year and succeeding year forecasts, and obtain results similar to those reported above. Immediately after forecasting EPS, analysts provide confidence ratings concerning the accuracy of their forecasts. Results indicate that confidence is lower in the inconsistent than the consistent track record conditions (means $=29.26$ and 40.83 , respectively; $F=11.47, p=.0015$ ), and in the relationship than the accuracy incentives conditions (means $=28.75$ and 40.87 , respectively; $F=10.64, p=.0022$ ). The interaction term is not significant ( $F=1.946$, $p=0.17$ ). This suggests that participants are aware of the added difficulty in predicting earnings in the inconsistent guidance bias condition as well as the effect of their failure to adjust for guidance bias where relationship incentives cause a conflict of interests.

11. Analysts completed another experiment prior to this. We create a dummy variable that denotes the experimental condition participants are in for the earlier experiment. We obtain the same results as our main analyses whether the dummy variable is included as a covariate or another variable that interacts with our main independent variable. The dummy variable is never statistically significant in any analyses. 
with the notion that analysts do not adjust for management guidance bias to avoid management missing analysts' forecasts and thereby maintaining a good relationship with management.

Finally, we ask the analysts to indicate the likelihood that Kappa's management was intentionally misguiding the market in its earnings guidance, using a nine-point scale $(1=$ extremely unlikely; $9=$ extremely likely). We find a main effect of track record in that analysts in the consistent condition view management as being significantly more likely to have intentionally misguided the market than those in the inconsistent condition (means $=7.54$ vs. 5.43 , respectively; $F=36.60, p=0.000$ ). The main effect of incentives $(p=0.778)$ and its interaction with track record ( $p=0.169)$ are not significant. These results suggest the following: (a) analysts are aware of a guidance track record indicating intentional bias on the part of management in the consistent condition; yet, those in the relationship condition fail to adjust for the bias while those in the accuracy condition do adjust; (b) uncertainty as to whether the guidance bias is intentional in the inconsistent track record condition might offer a convenient rationale for lack of adjustment for guidance bias when analysts face relationship incentives (e.g., elastic justification) or set a ceiling on adjustment due to the risk of causing a missed forecast.

\section{Experiment 2: Effect of magnitude of guidance bias}

A major finding in Experiment 1 is that analysts in the relationship condition fail to adjust for guidance bias whether the track record shows a consistent or inconsistent guidance pattern, even though an adjustment of one cent would still enable management to meet analysts' forecasts. The failure to adjust for guidance bias in the consistent bias setting is particularly striking because the consistent downward bias of one cent is observed in all three consecutive periods. It appears that analysts' incentives are for management to beat rather than merely meet analysts' forecasts. In Experiment 1, we employ a mean guidance bias of one cent $(\$ 0.01)$ to have external correspondence with the median guidance bias documented in empirical-archival studies (Baik and Jiang 2006). However, any adjustment of one cent or more implies that management will be unable to beat analysts' forecasts, a boundary condition for the operation for our theory (see flat line in Figure 1). In Experiment 2, we employ a larger guidance bias of two cents. With a larger guidance bias, analysts have room to partially adjust for the bias (by an average of one cent) to attain greater accuracy (Hong and Kubik 2003), while still allowing management to beat the analyst's forecasts. We expect that guidance bias adjustment will be larger when track record is consistent (when there is less elastic justification not to adjust) than when track record is inconsistent (when there is more elastic justification not to adjust), subject to the constraint that the adjustments still enable management to beat analysts' forecasts (see slope in Figure 1). 
TABLE 3

Experiment 2: Details of manipulations

Panel A: Consistent track record manipulation

\begin{tabular}{llllll}
\hline Year & $\begin{array}{c}\text { First } \\
\text { quarter }\end{array}$ & $\begin{array}{l}\text { Second } \\
\text { quarter }\end{array}$ & $\begin{array}{l}\text { Third } \\
\text { quarter }\end{array}$ & $\begin{array}{l}\text { Fourth } \\
\text { quarter }\end{array}$ & Year \\
\hline
\end{tabular}

Fiscal 2003

Guidance

Actual EPS

0.06

0.12

0.18

0.13

Fiscal 2004

Guidance

Actual EPS

0.19

0.15

Fiscal 2005

0.17

0.19

Guidance

Actual EPS

0.21

0.25

0.14

Fiscal 2006

Guidance

Actual EPS

0.19

0.16

0.51

Panel B: Inconsistent track record manipulation

\begin{tabular}{|c|c|c|c|c|c|}
\hline Year & $\begin{array}{c}\text { First } \\
\text { quarter }\end{array}$ & $\begin{array}{l}\text { Second } \\
\text { quarter }\end{array}$ & $\begin{array}{l}\text { Third } \\
\text { quarte }\end{array}$ & $\begin{array}{l}\text { Fourth } \\
\text { quarter }\end{array}$ & Year \\
\hline \multicolumn{6}{|l|}{ Fiscal 2003} \\
\hline Guidance & & & & 0.13 & \\
\hline Actual EPS & 0.06 & 12 & 0.18 & 0.15 & 0.51 \\
\hline \multicolumn{6}{|l|}{ Fiscal 2004} \\
\hline \multicolumn{6}{|l|}{ Guidance } \\
\hline Actual EPS & 0.19 & & 0.19 & 0.20 & 0.75 \\
\hline \multicolumn{6}{|l|}{ Fiscal 2005} \\
\hline Guidance & & & 0.12 & & \\
\hline Actual EPS & & 0.25 & 0.16 & 0.18 & 0.80 \\
\hline Fiscal 2006 & & & & & \\
\hline Guidance & & & & & \\
\hline Actual EPS & 0.19 & & & & \\
\hline
\end{tabular}

\section{Notes:}

Experiment 2 manipulates the firm's guidance track record by varying the consistency in the downward bias associated with management guidance issued by management in prior periods. All analysts are told that they have developed a good relationship with the firm's management over time (relationship incentives). Panels A and B show the firm's guidance track record that is shown to analysts. For both consistent and inconsistent Track Record manipulations, the average guidance bias over the three periods is a downward bias of two cents (-\$0.02). In the consistent Track Record manipulation, each period is associated with the same amount of downward bias of two cents. In the inconsistent Track Record manipulation, Fiscal 2003 has a downward bias of two cents, Fiscal 2004 has no bias, and Fiscal 2005 has a downward bias of four cents. 


\section{Method}

Experiment 2 involves two treatment conditions where the guidance bias is either consistent or inconsistent over time. Participants are 34 experienced sell-side financial analysts from another investment banking, trading, and brokerage firm. Eighteen of them are randomly assigned to the consistent condition, with the remaining sixteen assigned to the inconsistent condition. They complete the experiment over the participating firm's web-server. Their average experience as an analyst is 7.32 years, and twenty-eight of them are chartered financial analysts. ${ }^{12}$ Analysts who participate in Experiment 2 are not the same as those involved in Experiment 1.

The design is identical to that used in the relationship/consistent and relationship/inconsistent conditions in Experiment 1, except that the downward bias is doubled: consistently 2 cents for each period in the consistent condition, and 2 cents, 0 cents, and 4 cents in the inconsistent condition (see Table 3 for details).

\section{Results}

All analysts correctly answer the manipulation check questions on their relationship with management. On the question of whether prior period's management guidance is always too high, too low, or about right (1: much too low; 5: about right; 9: much too high), the mean response is 1.97 (range between 1 and 4). Thus, all analysts are aware that the guidance is downwardly biased. Finally, participants in the consistent track record condition all agree that management's guidance is different from actual earnings by the same amount each time such guidance is provided, and participants in the inconsistent condition all disagree with this statement.

Analysts' mean current quarter forecast is 19.33 cents (standard deviation $=0.69$ cents) in the consistent condition, reflecting an upward adjustment of 1.33 cents. As expected, this forecast is significantly higher than the management guidance of 18 cents $(t=8.246, p=0.000)$. However, the adjustment of 1.33 cents is significantly lower than the full guidance bias of two cents $(t=-4.123, p=0.001)$.

12. According to our prediction depicted in Figure 1, the combination of a flat line (as in Experiment 1) and a slope (as in Experiment 2) suggests an ordinal Experiment by Track Record interaction. ANOVA results reveals significant main effects $(p<0.026)$ and no interaction effect ( $p=0.914)$. However, the traditional ANOVA is not designed to detect ordinal interactions (Rosnow and Rosenthal 1995). To test for this ordinal interaction, we use a linear contrast of cell means recommended for testing this pattern (Buckless and Ravenscroft 1990; Rosnow and Rosenthal 1995), with weights of +3 for the Experiment 2/consistent cell, +1 for the Experiment 2/inconsistent cell, and -2 for the Experiment $1 /$ consistent and Experiment $1 /$ inconsistent cells. The contrast is statistically significant $(t=5.933, p=0.000)$, supporting the ordinal interaction pattern. A caveat to this analysis is that it involves data collected from different firms, over different time periods, and without complete randomization across all conditions. 
In the inconsistent condition, the mean current quarter forecast is 18.88 cents (standard deviation $=0.81$ cents), which reflects an adjustment of 0.88 cents. This forecast is significantly greater than the management guidance of 18 cents $(t=4.341, p=0.001)$, but the adjustment is significantly lower than the full adjustment of two cents $(t=-5.582, p=0.000)$. The adjustment is greater in the consistent condition than in the inconsistent condition ( $t=1.791, p=0.042$, one-tailed), consistent with our predictions. $^{13,14}$

\section{Conclusion}

We report the results of two experiments designed to explain why analysts do not adjust their forecasts to account for the tendency for firms to issue downwardly-biased guidance, even though they are aware of this tendency (e.g., Tan et al. 2002). In Experiment 1, we manipulate analysts incentives by instructing them either that their concern is about being accurate (accuracy incentives) or that they have developed a good relationship with management (relationship incentives). We demonstrate that when analysts are shown a track record of the firm's history of earnings and guidance, they will adjust for firm-specific guidance bias when they have accuracy incentives, but not when they have relationship incentives. This difference in bias adjustment as a function of incentives is larger when the guidance track record is inconsistent (vs. consistent). In the debriefing, analysts are unanimous in indicating that having the firm's actual earnings beat their forecast by a small amount improves relationships with management, but issuing a forecast above management's current guidance such that the firm fails to meet or beat the forecast harms such relationships. This strongly suggests that analysts believe that maintaining a good relationship with management matters in a post-Regulation FD environment. To the extent that maintaining good relationships with management is widely held to be important by analysts, our results suggest that this incentive is a significant factor in explaining why analysts do not adjust for management guidance bias, even when there is evidence of a consistent firm-specific guidance bias.

In Experiment 2, we find that when the magnitude of the average downward guidance bias increases to two cents (versus one cent in Experiment 1), analysts with relationship incentives partially adjust for the guidance bias both in the consistent and inconsistent track record conditions, with the adjustment larger in the former situation. Overall, our results in Experiments 1 and 2 are consistent with an elastic justification explanation (Hsee 1995), which posits that the extent to which analysts concerned with relationship incentives make adjustments for guidance bias is higher (lower) when management's guidance track record is consistent (inconsistent) over time; this elastic justification explanation is subject to the constraint that the adjustments do

13. Confidence in the forecasts is not significantly different between the consistent and inconsistent conditions ( $t=1.601, p=0.119)$. 
not create a risk of causing the reporting company to miss the forecast. When such adjustments might cause a missed forecast, adjustments are not made.

Prior research indicates that guidance bias in the marketplace is relatively small (around one cent) (DeGeorge, Patel, and Zeckhauser 1999; Baik and Jiang 2006), which suggests another reason why analysts might not adjust for this bias, as shown in Experiment 1. Nevertheless, results from Experiment 2 reveal that when the guidance track record bias is relatively large, analysts seem to tradeoff some accuracy with their desire to maintain a good relationship with management.

Overall, these findings contribute to the literature on analysts' forecasts by providing the first empirical evidence indicating conditions under which analysts will and will not adjust for bias in the guidance issued by management. Prior research finds that analysts generally fail to fully adjust for this bias. We show that, depending on the combination of guidance history consistency and analyst incentives, analysts fully adjust, partially adjust, or do not adjust for guidance bias. Our study has implications for regulators seeking to reduce analysts' conflict of interest through changes in firms' selective disclosures to analysts as well as reforms to analysts' compensation structures (Schroeder 2002). Our findings suggest that in a postRegulation FD environment, incentives to maintain a good relationship with management continue to motivate and influence analysts' judgments. Also, regulators may only be looking at part of the picture when they focus on analyst incentives (Schroeder 2002) in that the consistency of guidance track record matters. Finally, archival studies of responses to management guidance need to consider both accuracy and bias in management's guidance track record and analysts' differing incentives. Our results also indicate the possibility that other aspects of guidance track record, such as frequency and timing, can affect the impact of guidance on analysts' and investors' responses.

A caveat to interpreting our results is that our participating analysts do not face actual performance-contingent rewards as a function of their incentives, which they would in practice. Our constraint is that manipulating actual rewards that financially motivate such highly-paid analysts would be challenging and likely impractical. Furthermore, our design does not allow us to determine the specific manner in which analysts trade off maintaining accuracy and developing good management relationships. In an experimental setting with analysts as participants, we cannot be sure of the exact magnitude of the importance of accuracy versus pleasing management, because we cannot control the knowledge and experiences that these participants bring to the task. In addition, our findings related to management guidance history may not generalize beyond the specific pattern and magnitude of the guidance bias we employ in our experiments. For example, the guidance error in Experiment 2 is larger than the median bias documented in Baik and Jiang (2006). In Experiments 1 and 2 , we used a specific pattern of guidance error for the inconsistent 
guidance history condition, and our results may not generalize to other patterns of inconsistent guidance history. Another limitation is that the guidance track record is shown in a summary form which facilitates cognitive processing, although our discussions with analysts indicate that they keep similar records. Presumably, adjustments, if any, would be smaller and slower in circumstances where multiple firms are followed, patterns of bias are less obvious, and intervening information announcements degrade the learning environment. However, we note that even in this ideal learning environment, analysts fail to adjust fully for guidance bias in all situations involving high relationship incentives, regardless of the size of the guidance bias.

\section{References}

Affleck-Graves, J., L. Davis, and R. Mendenhall. 1990. Forecasts of earnings per share: Possible sources of analyst superiority and bias. Contemporary Accounting Research 6 (2): 501-17.

Antia, M., and C. Pantzalis. 2006. Security analyst incentives and quality of analyst generated information. Journal of Investing 15 (1):50-6.

Baik, B., and G. Jiang. 2006. The use of management forecasts to dampen analysts' expectations. Journal of Accounting and Public Policy 25 (5): 531-53.

Bartov, E., D. Givoly, and C. Hayn. 2002. The rewards to meeting or beating earnings expectations. Journal of Accounting and Economics 33 (2): 173-204.

Brown, L. D. 2001. A temporal analysis of earnings surprises: Profits versus losses. Journal of Accounting Research 39 (2); 221-41.

Buckless, F. A., and S. P, Ravenscroft. 1990. Contrast coding: A refinement of ANOVA for behavioral analysis. Accounting Review 65 (4): 933-45.

Choi, J. H., and D. A. Ziebart. 2002. A reexamination of bias in management earnings forecasts. Working paper, Hong Kong University of Science and Technology.

Cotter, J., A. I. Tuna, and P. D. Wysocki. 2006. Expectations management and beatable targets: How do analysts react to explicit earnings guidance?

Contemporary Accounting Research 23 (3): 593-624.

Cox, C. 2005. Response letter to Senator Ron Wyden regarding issuer retaliation against research analysts. Securities and Exchange Commission (September 1, 2005)

DeGeorge, F. J. Patel, and R. Zeckhauser. 1999. Earnings management to exceed thresholds. Journal of Business 72 (1): 1-33.

Dugar, A., and S. S. Nathan. 1995. The effect of investment banking relationships on financial analysts' earnings forecasts and investment recommendations.

Contemporary Accounting Research 12 (1): 131-60.

Hong, H., and J. D. Kubik. 2003. Analyzing the analysts: Career concerns and biased earnings forecasts. Journal of Finance 58 (1): 313-51.

Hsee, C. K. 1995. Elastic justification: How tempting but task-irrelevant factors influence decisions. Organizational Behavior and Human Decision Processes 62 (3): $330-37$. 
Hunton, J. E., and R. A. McEwen. 1997. An assessment of the relation between analysts' earnings forecast accuracy, motivational incentives and cognitive information search strategy. Accounting Review 72 (4): 497-515.

Ke, B., and Y. Yu. 2006. The effect of issuing biased earnings forecasts on analysts' access to management and survival. Journal of Accounting Research 44 (5): 9651000 .

Koonce, L., and M. Mercer. 2005. Using psychology theories in archival financial accounting research. Journal of Accounting Literature 24: 175-214.

Levitt, A 1998. The numbers game. Remarks by Chairman Arthur Levitt, Securities and Exchange Commission, delivered at the NYU Center for Law and Business, New York (September 28).

Libby, R., R. Bloomfield, and M. W. Nelson. 2002. Experimental research in financial accounting. Accounting, Organizations and Society 27 (8): 775-810.

Libby, R., J. E. Hunton, H. T. Tan, and N. Seybert. 2008. Relationship incentives and the optimistic/pessimistic pattern in analysts' forecasts. Journal of Accounting Research 46 (1): 173-98.

Libby, R., H. T. Tan, and J. E. Hunton. 2006. Does the form of managements' earnings guidance affect analysts' earnings forecasts? Accounting Review 81 (1): 251-70.

Lin, H.-W., and M. F. McNichols. 1998. Underwriting relationships and analysts' earnings forecasts and investment recommendations. Journal of Accounting and Economics 25 (1): 101-28.

Matsumoto, D. A. 2002. Management's incentives to avoid negative earnings surprises. Accounting Review 77 (3): 483-514.

Mayew, W. J. 2008. Evidence of management discrimination among analysts during earnings conference calls. Journal of Accounting Research 46 (3): 627-659.

Richardson, S. A., S. H. Teoh, and P. D. Wysocki. 2004. The walkdown to beatable analyst forecasts: The roles of equity issuance and insider trading incentives.

Contemporary Accounting Research 21 (4): 885-924.

Rosnow, R. L., and R. Rosenthal. 1995. Some things you learn aren't so: Cohen's paradox, Asch's paradigm, and the interpretation of interaction. Psychological Science 6 (1): 3-9.

Schipper, K. 1991. Commentary on analysts' forecasts. Accounting Horizons 5 (4): $105-21$.

Schroeder, M. 2002. SEC to consider step in analysts' independence. Wall Street Journal C7, September 9.

Schweitzer, M. E., and C. K. Hsee. 2002. Stretching the truth: Elastic justification and motivated communication of uncertain information. Journal of Risk and Uncertainty 25 (2): 185-201.

Skinner, D. J., and R. G. Sloan. 2002. Earnings surprises, growth expectations, and stock returns or don't let an earnings torpedo sink your portfolio. Review of Accounting Studies 7 (2-3): 289-312.

Soffer, L. C., S. R. Thiagarajan, and B. R. Walther. 2000. Earnings preannouncement strategies. Review of Accounting Studies 5 (1): 5-26. 
Springsteel, I. 2003. Do the new research rules matter? Companies still seek out underwriters whose analysts are bullish. Investment Dealers' Digest (March 10): 1.

Tan, H. T., R. Libby, and J. E. Hunton. 2002. Analysts' reactions to earnings preannouncement strategies. Journal of Accounting Research 40 (1): 223-46. 